\title{
Space and time harmonics related problems and their mitigation for position and speed sensorless slip-ring induction motor drives applications
}

\author{
SUBHASIS NANDI \\ University of Victoria, Department of Electrical and Computer Engineering, \\ Victoria, BC, Canada, V8W 3P6 \\ e-mail:snandi@ece.uvic.ca
}

\begin{abstract}
There have been renewed interests in slip-ring induction machines due to their increasing use in both grid connected and stand-alone wind power generation schemes. Despite the squirrel cage induction generators' advantages of being brushless, low-cost, needing less maintenance and having inherent overload protection, the biggest advantage of variable-speed wound rotor induction machines is in its doubled energy capture. Also in high power induction motor drives such as static Kramer drives or static Scherbius drives use of wound rotor induction motors is a must. Thus it becomes necessary to measure the speed of the machine for closed loop control for such high performance drives. Recently, a sensorless position and speed estimation scheme was proposed for wound rotor wind power generator. In this paper, the limitation of the scheme caused by space and time harmonics have been investigated. Simulation results have been presented to explain the mechanism of the space and time harmonics caused distortion of current. Experimental results showing the deterioration of speed detection scheme at light load for a slip-ring induction motor have been presented. Finally, improvements have been applied experimentally to obtain better speed estimation.
\end{abstract}

Keywords. Speed estimation; slip-ring induction machines.

\section{Introduction}

Constant speed constant frequency (CSCF) based wind energy conversion systems (WECS) using squirrel cage induction generators remain the most popular scheme to harness wind power (Datta \& Ranganathan 2002), primarily because of their low-cost, design simplicity, absence of brushes, minimal maintenance and inherent overload protection (Chatterjee et al 2007). However squirrel cage induction machines are used only in low-power turbines. Also their use severely underutilizes the turbine capacity. Most importantly, in a constant speed system the transient mechanical loading due to persistent torque fluctuations reduce life of gear-box and cause additional structural cost. Hence variable speed systems are used with such machines to improve the energy capture. Variable speed system also helps in absorbing 
mechanical loads by using the inertia of turbine blades for temporary energy storage, thereby acting as buffer.

A further amelioration of an equivalent order over the squirrel cage machines with variable speed systems is possible with wound rotor or synchronous machines (PM or field excited). Typical wind turbine designs today range between 1.5 and $3 \mathrm{MWs}$ using either doubly fed induction machine or synchronous machine. However, it has been shown that a WECS employing variable speed wound rotor induction generator can extract double the rated power from the turbine in the supersynchronous mode (Datta \& Ranganathan 2002). While this may not always be the primary motivation for selecting a drive, additional energy capture has an added value in terms of reduced energy cost. Thus the role of slip-ring induction generator in wind power generation can certainly be vindicated.

Apart from the wind power applications, slip-ring motors are always used for slip power recovery drives that find wide application in large capacity pumps and fan drives, shipboard variable speed constant frequency (VSCF) systems, variable speed hydro pumps and generators and utility system flywheel energy (Bose 2002).

The basic drive topologies used for doubly fed induction machines are shown in figure 1 . Figure 1 (top) shows (Bose 2002), (Datta \& Ranganathan 2002) the configuration normally used in static slip-power recovery drives and WECS. Though both motoring and generation is possible this way, smooth speed reversal is not possible with such a scheme. The second arrangement shown (Poddar \& Ranganathan 2004) in figure 1b has the capability of fourquadrant operation and hence is more versatile.

Regardless of the application, sensorless position and speed (the term 'speed' is used extensively in IEE and IEEE Transactions instead of 'angular velocity' even for rotating machines) control drives are always preferred because sensors are often costly, fragile and have reliability problems. Various sensorless speed estimation methods have been listed in Bose (2002). They are based on a) slip calculation, b) state estimation, c) model reference adaptive system (MRAS), d) speed adaptive flux observers (Luenberger observers), e) extended Kalman filter $(E K F), f)$ slot harmonics, g) injection of auxiliary signals. More on sensorless speed control can be found in the Jiang \& Holtz (1995); Kim et al (1994); Nandi et al (2003); Rajashekara et al (1996); Vas (1998). Most of these methods assume that rotor current is not accessible which happens to be true only in case for squirrel cage induction machines. However, for slipring machines this is not so. Since both rotor and stator side current fundamental frequencies are known, speed detection becomes a relatively simple task. In order to avoid integration drift errors one might even be tempted to determine rotor position first (provided the motor parameters are known and do not vary with temperature, aging and operating conditions) and then the rotor speed from that position information. One such method has recently been proposed for a VSCF drive application (Datta \& Ranganathan 2002). The position and speed sensing is based on a recursive approach where rotor current space vector position is determined in both stator and rotor reference frame. The speed is then determined indirectly by differentiating the smooth sinusoidal and co-sinusoidal functions derived from the difference of these two positions with respect to time. The rotor current space vector in stator co-ordinates is obtained by estimating only the magnitude of the stator magnetizing current space vector in rotor co-ordinates and then reorienting it in stator co-ordinates by using the position information from the stator voltage space vector. The rotor position information is however required to be fed back to obtain the 'magnitude only' information of the stator magnetizing current space vector. Since this is done with only one sample time delay, the algorithm yields position and speed estimates very fast and is only limited by the filter used at the end stage of the speed estimation process. 
As long as the rotor currents are of reasonably high magnitude, this algorithm gives excellent results. However once the rotor current falls below a certain value, the harmonics in the rotor current start to play a significant role in determining the speed information. It may be argued that the stator currents may also have their fare share of harmonics and may also contribute to this problem. However since in most of the applications the magnetizing current flows in the stator, this problem will not be encountered until the magnetizing current has decreased significantly which happens when the machine operates in the flux weakening region. Also, often the utility may also have significant $3^{\text {rd }}, 5^{\text {th }}, 7^{\text {th }}$, etc. harmonics. They will also cause problem in speed detection under no-load. For a configuration such as figure $1 \mathrm{~b}$, the low order time harmonic effects can be minimized since both stator and rotor are supplied from converters. This scheme also has an added advantage of allowing the stator and rotor

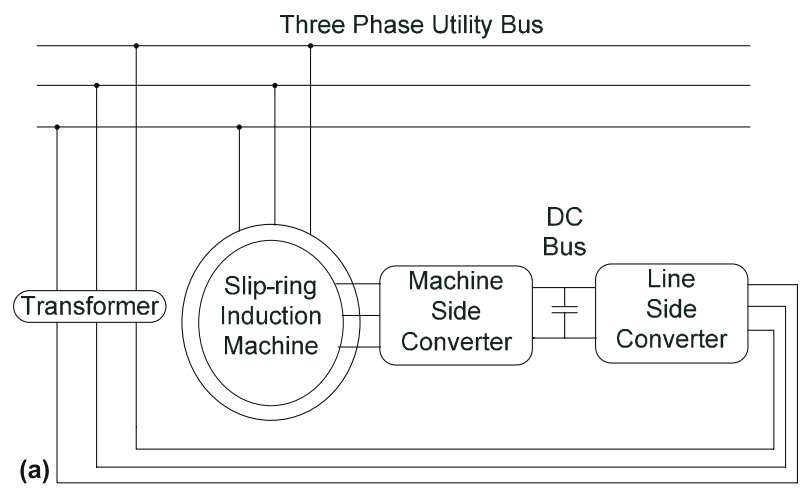

(a)

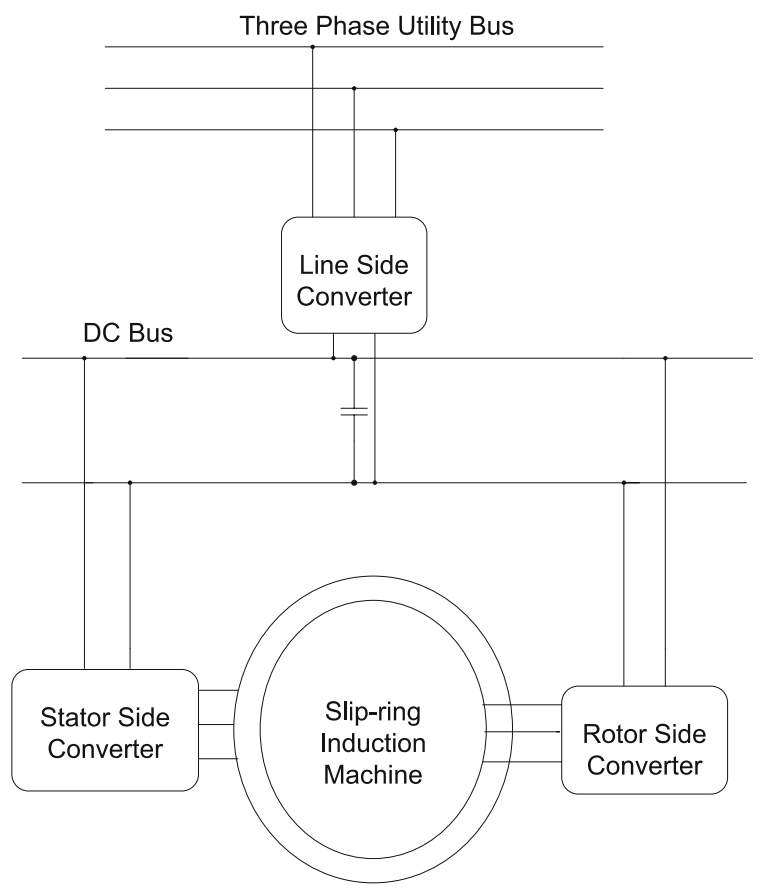

Figure 1. (a) Conventional rotor side control of slip-ring induction motor and (b) improved configuration with both stator and rotor side control. 
share the magnetizing current equally (Poddar \& Ranganathan 2004). Hence the speed detection problem under no-load will be much less compared to the drive described in figure 1a. However, the rotor and the stator currents still need some filtering due to space harmonic effect as will be described in the main body of the paper.

The paper is written in the following order. First, the position and speed detection scheme is briefly discussed and the problem arising in the estimation process due to the rotor harmonic currents is described. Secondly, the role played by time and space harmonics in generating harmonics in the stator and rotor line current is explored using simulated data. Finally, a mitigation technique, based on multiple filter assignments for strategic parameters, has been demonstrated both through simulation and experiments.

\section{Position and speed detection algorithm (Datta \& Ranganathan 2002)}

The speed detection algorithm can be briefly discussed using figures 2 and 3 . The positions of different current and voltages involved are first described in figure 2. The stator resistance and leakage reactance are assumed small. Here $\theta$ is the angle of reference of the stator voltage space phasor in stator co-ordinates. $\rho_{1}$ and $\rho_{2}$ are the rotor current space vector angles in stator and rotor co-ordinates respectively. $\varepsilon$ denotes the rotor position with respect to stator. The speed detection algorithm takes the rotor current $\bar{i}_{r r}$, stator current $\bar{i}_{s s}$ and voltage space vectors $\bar{v}_{s s}$ in their respective frame of references as input. The estimated $\cos (\varepsilon)$ and $\sin (\varepsilon)$ terms are fed back with one sample delay and $\bar{i}_{r r}$ is changed to stator reference frame by using the following relationship,

$$
\bar{i}_{r s(e s t)}=\bar{i}_{r r} e^{j \varepsilon} \text {. }
$$

Next the stator magnetizing current vector magnitude is estimated from,

$$
\left|\bar{i}_{m s}\right|=\left|\bar{i}_{r s(e s t)}+\left(1+\sigma_{s}\right) \bar{i}_{s s}\right| .
$$

Since stator resistance and leakage reactance has been assumed as negligible, applied voltage space vector is in quadrature (leading) with $\bar{i}_{m s}$. Thus the angle information $\theta$ can now be used to compute $\bar{i}_{r s}$ by manipulating (2) as,

$$
\bar{i}_{r s} \approx\left|\bar{i}_{m s}\right| \cdot e^{j\left(\theta-90^{\circ}\right)}-\left(1+\sigma_{s}\right) \bar{i}_{s s},
$$

from which $\cos \left(\rho_{1}\right), \sin \left(\rho_{1}\right)$ can be estimated as shown in figure 3. Similarly $\cos \left(\rho_{2}\right), \sin \left(\rho_{2}\right)$ can also be computed from $\bar{i}_{r r}$.

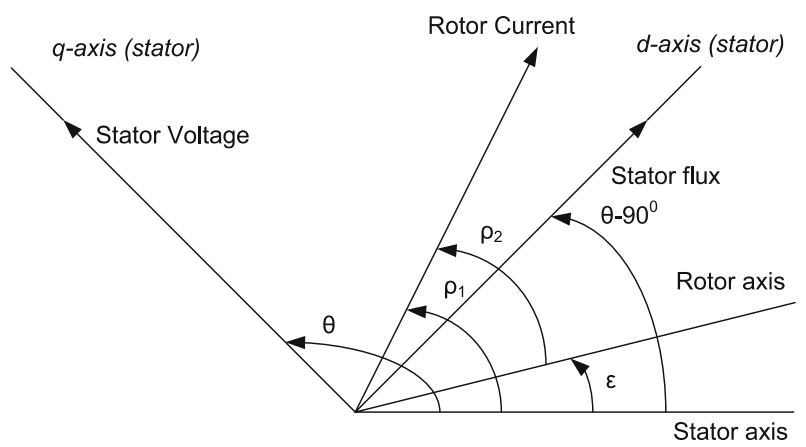

Figure 2. Position of different voltages and current stator co-ordinates. 


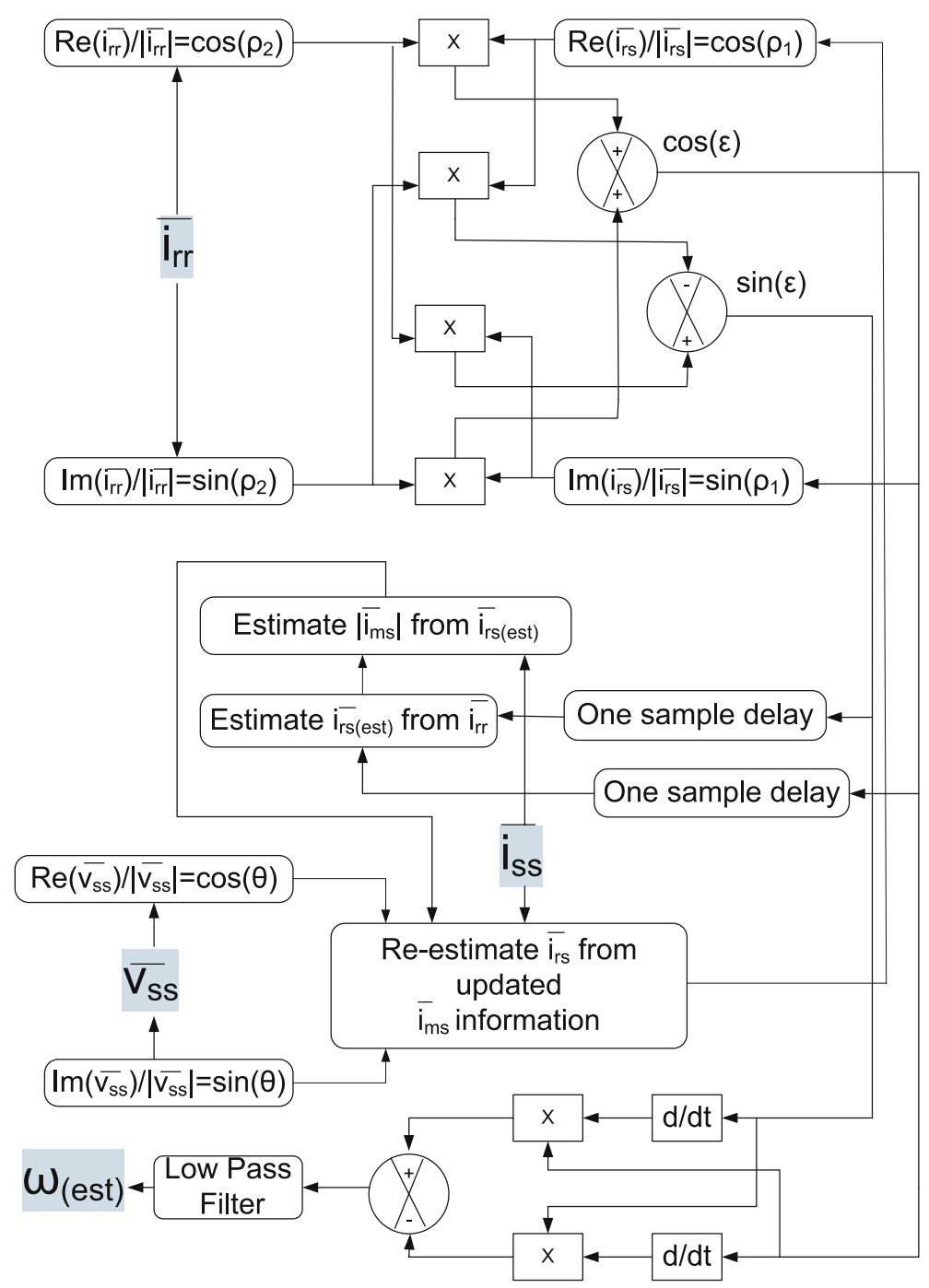

Figure 3. Position and speed estimation scheme.

With

$$
\varepsilon=\rho_{1}-\rho_{2},
$$

as shown in figure 2, position in terms of $\cos (\varepsilon)$ and $\sin (\varepsilon)$ can be calculated from $\cos \left(\rho_{1}\right), \sin \left(\rho_{1}\right), \cos \left(\rho_{2}\right), \sin \left(\rho_{2}\right)$. Computation of speed is then straightforward following

$$
\frac{d \varepsilon}{d t}=\cos (\varepsilon) \frac{d\{\sin (\varepsilon)\}}{d t}-\sin (\varepsilon) \frac{d\{\cos (\varepsilon)\}}{d t} .
$$

The speed estimate $\omega_{(e s t)}$ is obtained from $\frac{d \varepsilon}{d t}$ after passing this signal through a low pass filter. 


\section{Effect of space and time harmonics on stator and rotor currents}

The winding structure of an ac machine makes it behave like an antenna in some sense. It means that in a specific type of winding a particular time harmonic will be induced if and only if any pole pair (or mode) number associated with it matches that of the voltage inducing flux wave (Kron 1951). Also, the flux produced by stator current links the rotor and vice versa. Whenever flux from one frame of reference or co-ordinate system links another, the relative difference in speed has to be factored in as follows. Suppose a component of flux density in stator reference frame is given by

$$
B_{s s}=B_{m 1} \cos \left(n p \theta \pm \omega_{e} t+\varsigma_{1}\right) .
$$

The '-' sign comes before $\omega_{e}$, the time harmonic in rad/sec. in (6) when the field is forward rotating and is ' + ' when it is reverse rotating (Sen 1997). $p$ is the number of fundamental pole pairs, $n$ is the space harmonic number while $\zeta_{1}$ is an arbitrary phase angle. If now the rotor rotates at a speed $\omega$, then the same component with respect to rotor co-ordinates can be given as,

$$
B_{s r}=B_{m 1} \cos \left[n p(\phi+\omega t) \pm \omega_{e} t+\varsigma_{1}\right]
$$

or

$$
B_{s r}=B_{m 1} \cos \left[n p \phi+\left\{n p \omega t \pm \omega_{e} t\right\}+\varsigma_{1}\right],
$$

with $\phi$ the angle of reference in rotor co-ordinates is related to $\theta$ as

$$
\theta=\phi+\omega t
$$

Similarly, a flux density component $B_{r r}$ in rotor reference frame will appear in the stator reference frame as,

$$
B_{r s}=B_{m 2} \cos \left[n p \theta+\left\{-n p \omega t \pm \omega_{f} t\right\}+\varsigma_{2}\right],
$$

where $\omega_{f}$ is the rotor frequency.

Thus in a slip-ring motor with regular three phase integral slot winding $(n=1,6 k \pm 1, k=$ $1,2,3, \ldots)$ on both stator and rotor, any time harmonic in stator will get induced in rotor and vice-versa as a different time harmonic, modulated by the effect of space harmonics. For example, if $p=2, n=5, \omega_{e}=2 * \pi * 60, \omega=2 * \pi * 28.5 \mathrm{rad} . / \mathrm{sec}$., then the frequency of voltage induced in the rotor, considering forward rotating field, becomes $5 * 2 * 28.5+60=$ $345 \mathrm{~Hz}$ (using the expression within the curly brackets in (8)), rotating in the reverse direction. Similarly, with $p=2, n=5, \omega_{f}=2 * \pi * 3, \omega=2 * \pi * 28.5 \mathrm{rad} . / \mathrm{sec}$., the frequency of voltage induced in the stator becomes $5 * 2 * 28 \cdot 5-3=282 \mathrm{~Hz}$ (using the expression within the curly brackets in (10)), rotating in the forward direction. For a squirrel cage machine it may not be true since the rotor has shortened bars whose winding distribution can have different number of pole pairs.

Now, usually the stator supplies the magnetizing current when connected to the grid. Thus the fundamental stator current is about 30\%-50\% (Sen 1997) of full load current even under no-load conditions and the effect of these harmonics in stator can be kept minimal even up to double the speed in the supersynchronous mode of operation. However under no load condition the fundamental current in rotor is almost zero. Therefore, under light load the total 
harmonic distortion (THD) of rotor current will be very high considering the space and time harmonic induced currents in the rotor. Now, if the speed is calculated the way as shown in $\S 2$ with high THD in rotor current, there is going to be significant estimation error since $\rho_{2}$ is computed assuming that rotor currents are purely sinusoidal in nature. As described earlier, this problem can only be minimized by following the scheme shown in figure $1 \mathrm{~b}$ where the option of splitting the magnetizing current is equally available. However the problem caused by the space harmonics will still exist. These harmonics will translate as time harmonics from one side to the other as described in the previous paragraph.

\section{Simulated sensorless position and speed estimation}

A $2 \mathrm{~kW}, 4$ pole, $60 \mathrm{~Hz}, 208 \mathrm{~V}, 3$-ph wound-rotor motor, with star connected stator and rotor was simulated with large number of space harmonics using a technique similar to the one in Joksimovic (2007), as a standard wound-rotor motor supplied from the utility with the rotor terminals short-circuited. The mutual and magnetizing inductances of the machine are computed using the Winding Function Approach (WFA), which can include any number of space harmonics in the inductance computations. Then the coupled circuit equations for the stator and rotor are solved using MATLAB (2007). The motor was first simulated under full load such that $\omega_{e}=2 * \pi * 60, \omega=2 * \pi * 28.5$ and $\omega_{f}=2 * \pi * 3 \mathrm{rad} . / \mathrm{sec}$. The rotor and the stator currents and their harmonics under full load are shown in figures 4 and 5 respectively. The harmonic spectra have been normalized with respect to the largest magnitude component, which is set to zero $\mathrm{dB}$. The frequency spectrum of the rotor current clearly shows the fundamental $3 \mathrm{~Hz}$ component, the stator $5^{\text {th }}$ space harmonic related $5 * 2 * 28 \cdot 5+60=345 \mathrm{~Hz}$ component and the stator $7^{\text {th }}$ space harmonic related $7 * 2 * 28.5-60=339 \mathrm{~Hz}$ component. Similarly, stator currents show the $5 * 2 * 28 \cdot 5-3=282 \mathrm{~Hz}$ and $7 * 2 * 28 \cdot 5+3=402 \mathrm{~Hz}$ components.

Next, the motor was simulated under no-load condition. Since slip is reduced to zero, the corresponding values of $\omega_{e}, \omega, \omega_{f}$ are $2 * \pi * 60,2 * \pi * 30$ and 0 rad./sec. respectively. Comparison of rotor and stator currents and their spectra as before (figures 6 and 7) reveal that while there are no noticeable differences in the harmonic current magnitudes of the stator, the biggest component in the rotor current corresponds to $5 * 2 * 30+60=360 \mathrm{~Hz}$ ! The fundamental component $(0 \mathrm{~Hz})$ is only around $-37.5 \mathrm{~dB}$. Hence computation of $\rho_{2}$ and hence speed will now be corrupted with higher order harmonics. That will result in incorrect estimation of position and speed as can be seen clearly from figure 8 . The reason can be easily explained by examining figure 6 . With a highly distorted rotor current, $\rho_{2}$ is calculated incorrectly from the space vector $\bar{i}_{r r}$. This can be easily verified from the plot (figure 8) of $\cos \left(\rho_{2}\right)$, computed for the steady state condition as depicted in figure 9. Calculation of $\rho_{1}$ will not be affected to a large extent since it is calculated using $\bar{i}_{r s}$ which is obtained from (3). It can be argued that calculation of $\bar{i}_{m s}$ also uses $\bar{i}_{r r}$ and hence corrupt the calculation. Since $\left|\bar{i}_{s s}\right| \gg\left|\bar{i}_{r r}\right|$ under no-load, the effect of $\bar{i}_{r r}$ can be deemed as minimal.

With some small and finite value of rotor current, as would be in the case for an actual machine under light load condition, the speed estimation is much improved. However, the estimated speed under light load condition still has lot of noise as can be seen from figure 10 . This may lead to stability problem of the drive as distorted feedback signals have been reported to deteriorate the dynamic performance of the drive system (Jiang \& Holtz 1995), in case such a noisy estimated speed is used for control purpose.

Since both stator and rotor currents contain harmonics, their minimization is expected to improve the quality of estimated speed. This can be achieved by simple filtering. However, 

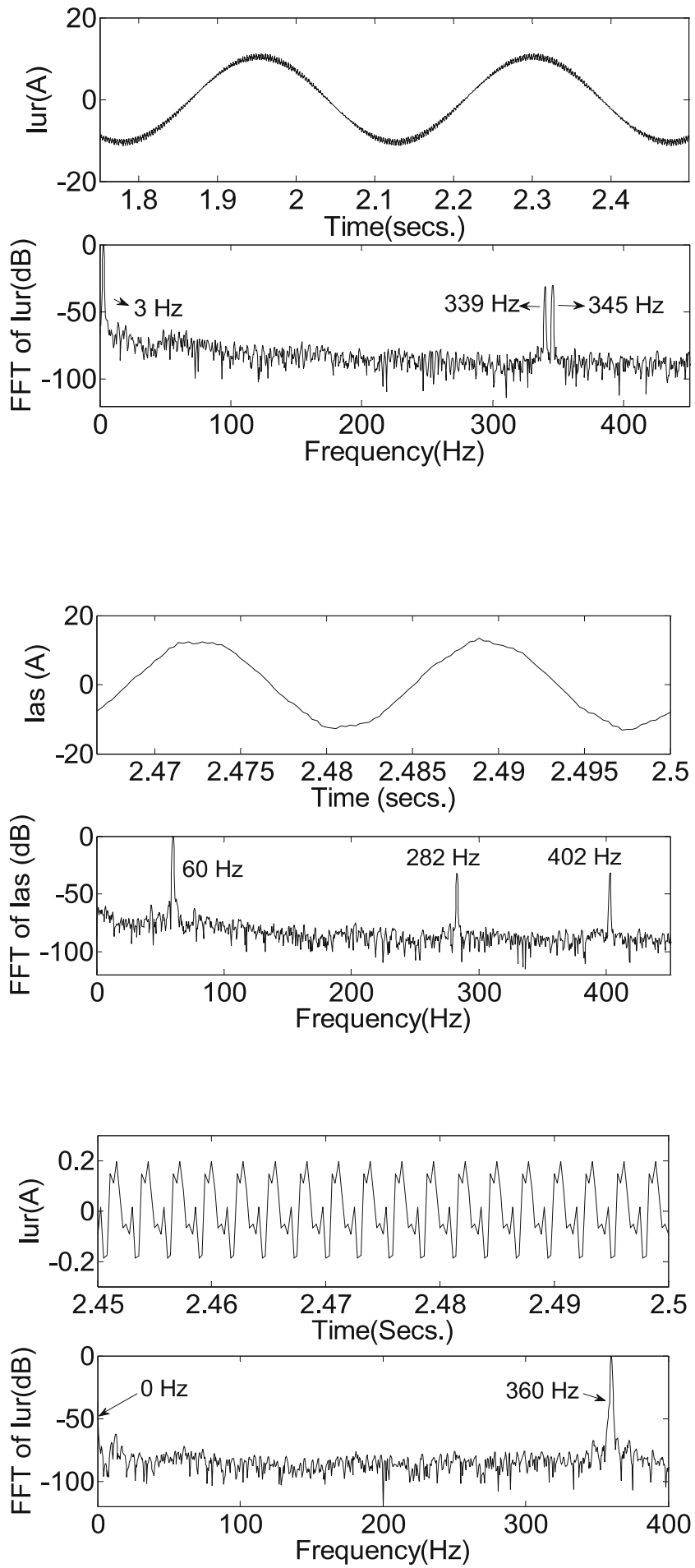

Figure 4. Rotor line current $I_{u r}$ and its spectra under full load.

Figure 5. Stator line current $I_{a s}$ and its spectra under full load.

Figure 6. Rotor line current $I_{u r}$ and its spectra under no-load. 

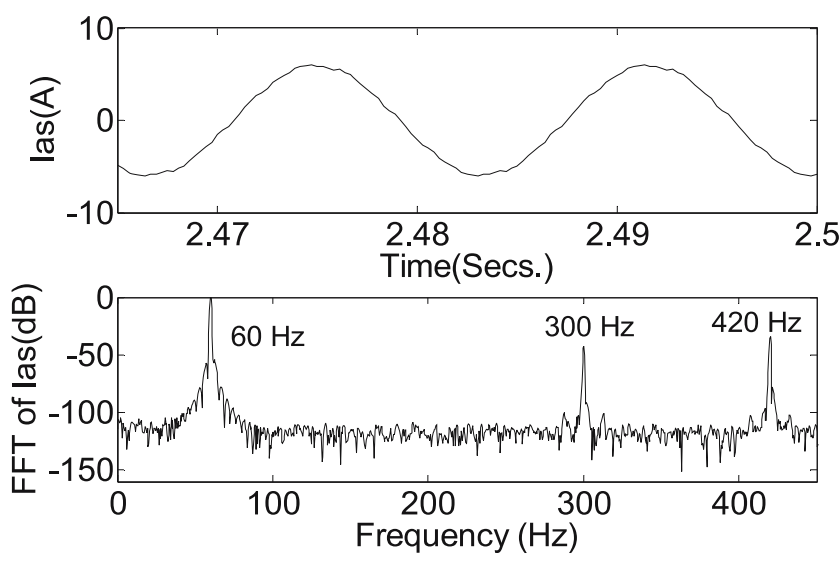

Figure 7. Stator line current $I_{a s}$ and its spectra under no-load.

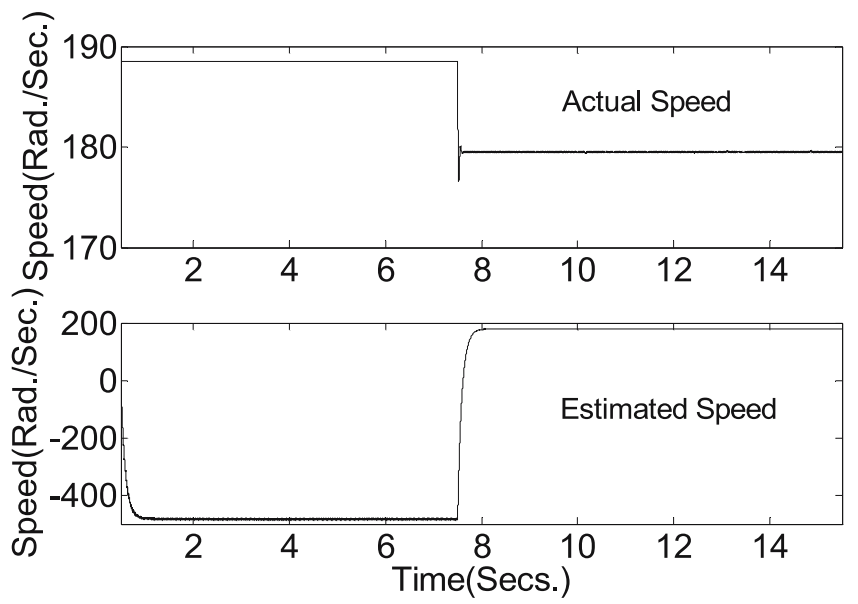

Figure 8. Actual and estimated speed under no-load and full load.

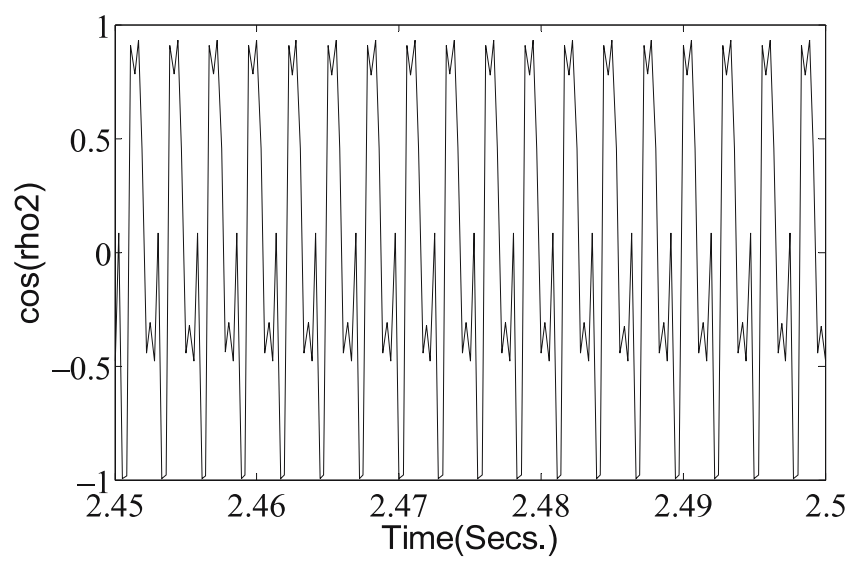

Figure 9. $\cos \left(\rho_{2}\right)$ computed from no-load rotor current. 
because of the large THD of the rotor line current under light load condition, a simple first order finite impulse response (FIR) did not seem to improve the speed estimation considerably. Hence a simple first order infinite impulse response (IIR) filter is envisaged to perform the filtering operation. Based on ease and speed of on-line filter coefficient calculation in digital domain, good performance under transient condition, a low pass first order Butterworth filter in its digital form is considered for the application. This can be easily obtained from the analog form using the following procedure (Proakis \& Manolakis 1997). Suppose the analog form of the filter is

$$
H(s)=\frac{a}{s+a} .
$$

Applying bilinear transformation, i.e. with

$$
s=\frac{2}{T_{s}} \frac{1-z^{-1}}{1+z^{-1}},
$$

where $T_{s}$ is the sampling time,

$$
H(z)=\frac{\frac{\left(a T_{s} / 2\right)\left(1+z^{-1}\right)}{1+a T_{s} / 2}}{1-\frac{\left(1-a T_{s} / 2\right)}{1+a T_{s} / 2} z^{-1}} .
$$

Suppose, the cut-off frequency is $72 \mathrm{~Hz}$. Therefore $a=2 * \pi * 72 \mathrm{rad} . / \mathrm{sec}$. With a sampling frequency of $3600 \mathrm{~Hz}, T_{s}$ is $1 / 3600 \mathrm{sec}$. Then

$$
H(z)=\frac{0 \cdot 0592\left(1+z^{-1}\right)}{1-0.882 z^{-1}} .
$$

Then the difference equation to implement the filter will be

$$
Y(z)=0.882 Y(z-1)+0.0592(X(z)+X(z-1)),
$$

where $X(z), Y(z)$ are the current values of the unfiltered and filtered signals, and $X(z-$ 1), $Y(z-1)$ the previous values of unfiltered and filtered signals.

This type of filtering have been applied for stator, rotor estimated magnetizing current space vectors and also the speed. However, different cut-off frequencies are not fixed but adaptive and have to be set for these filters based on fundamental frequencies of current space vectors, speed and required dynamic response. Also some of these filters can be employed only when the load is low. As a first approximation, the cut-off frequencies of the current filters are chosen slightly higher than the maximum operating frequencies in stator and rotor. The speed filter cut-off is selected based on the noise spectrum produced by the differentiation process. These filters will give rise to large error in estimated speed at start-up and the estimated position would not be able to catch up with the actual position. Hence initially, the computed slip can be forced to zero till the speed signal settles down (Datta \& Ranganathan 2002). For example, with cut-off frequencies of $3 \mathrm{~Hz}$ for both estimated magnetizing current magnitude and rotor current space vector, $1.8 \mathrm{~Hz}$ for the speed estimation and $72 \mathrm{~Hz}$ for stator current the estimated plot as shown figure 11 (top) has been obtained. Other than the slight increase in the overshoot (transient estimation error) at the speed transition point, the response seems quite the same as shown in figure 10, which also used an identical magnetizing current filter but no other filter. Increasing the magnetizing current magnitude filter time constant to $1 \mathrm{~ms}$ as suggested 


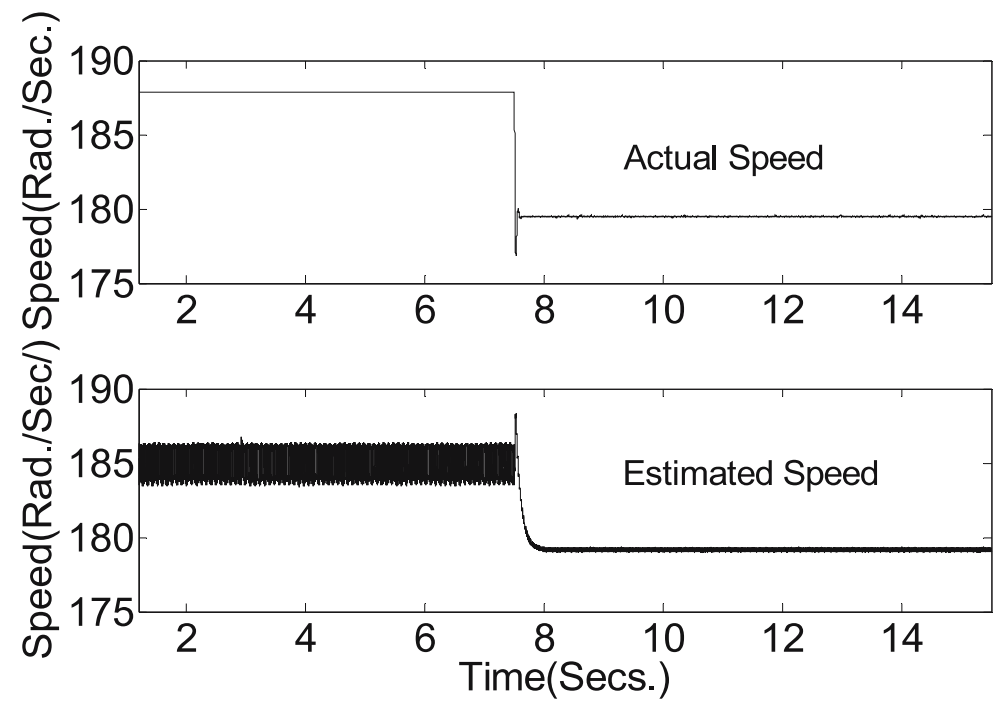

Figure 10. Actual (simulated) and estimated speed under light load and full load.

in (Datta \& Ranganathan 2002), keeping other filters as they are, seems to not only increase the steady state ripple in the estimated speed and but also transient speed overshoot slightly (figure 11, bottom). However the transient speed estimation delay has not been affected to a great extent. The position estimation of $\rho_{2}$ in terms of $\cos \rho_{2}$ for the filter values chosen for figure 11 (top) has been shown in figure 12 which shows good quality position detection. Good quality position detection for small value of slip or light load condition can be clearly seen. Intuitively, there is an apprehension that the current filters may cause considerable phase and magnitude error since their cut-off frequencies are very close to their fundamental frequencies, particularly when the load is high. However, comparison of the actual speed (figure 10, top)
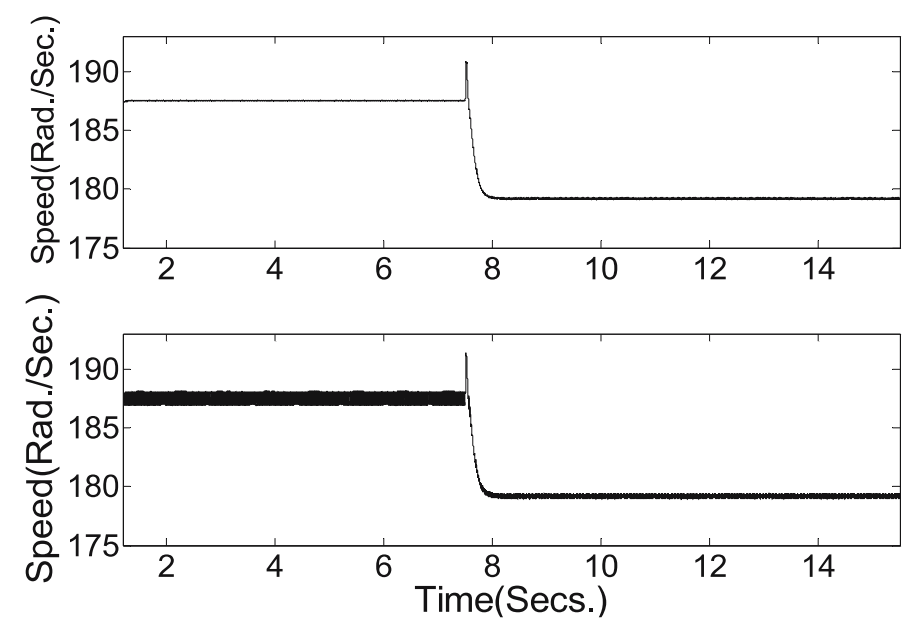

Figure 11. Speed estimates with different magnetizing current amplitude filter. 


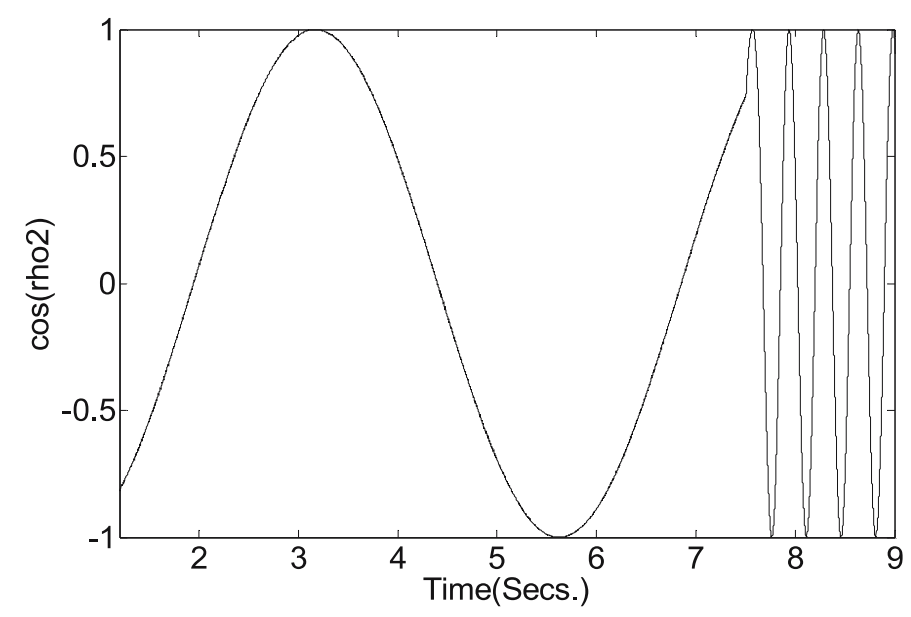

Figure 12. $\cos \left(\rho_{2}\right)$ computed from part-load rotor current after using filters that resulted in speed estimation as shown in figure 11 (top).

with the estimated speed (figure 11, top) at full load shows that does not seem to be the case.

\section{Experimental results}

Experiments were conducted on a slip-ring induction motor similar to the simulated one. It was run as a motor from utility supply and the speed was measured using a magnetic disc sensor. The stator and the rotor currents of the motor and their spectra under full load are shown in figures 13 and 14 respectively. There are many harmonics caused not only by space harmonics, but also by time harmonics as well in both stator and rotor. For example, the $5^{\text {th }}$ and the $7^{\text {th }}$ time
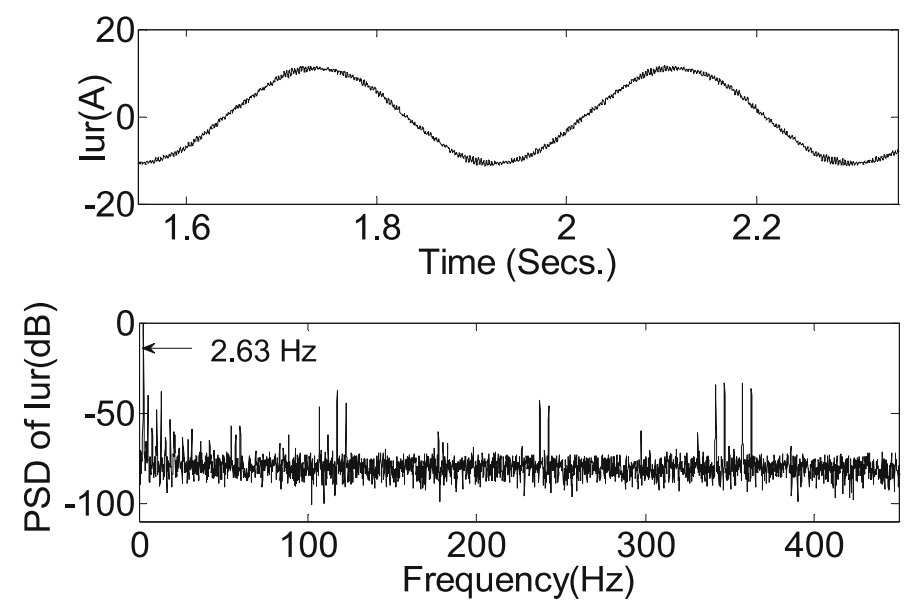

Figure 13. Experimental rotor line current $I_{u r}$ and its spectra under full load. The large (above $-50 \mathrm{~dB}$ ) frequency components between 300 and $400 \mathrm{~Hz}$ are st $341 \cdot 52,346 \cdot 8,357.36$ and $362.64 \mathrm{~Hz}$. 


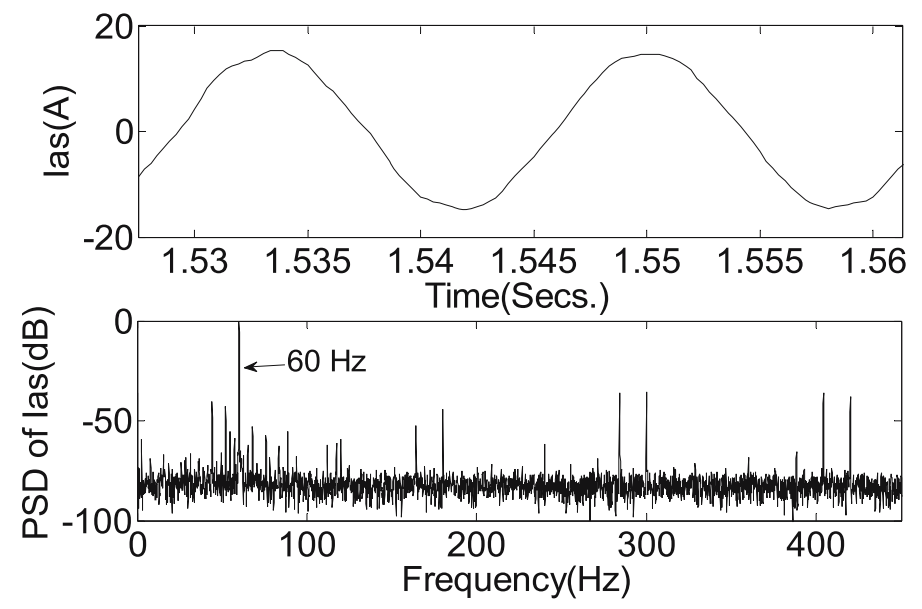

Figure 14. Experimental stator line current $I_{a s}$ and its spectra under full load. Apart from large (above $-50 \mathrm{~dB}$ ) frequency components 284.17 and $404.15 \mathrm{~Hz}$ are time harmonic related components such as 300 and $420 \mathrm{~Hz}$ exist.

harmonic are very strong in stator supply. As a result, with $\omega_{e}=2 * \pi * 60, \omega=2 * \pi * 28.68$ and $\omega_{f}=2 * \pi * 2.64 \mathrm{rad} . / \mathrm{sec}$., they appear as 357.36 and $362.64 \mathrm{~Hz}$ components in the rotor, apart from the space harmonic related frequency components in the rotor current at 346.8 and $341 \mathrm{~Hz}$. Similarly the 300 and $420 \mathrm{~Hz}$ time harmonic related components appear along side with the space harmonic related components of 284.17 and $404.15 \mathrm{~Hz}$ components in the stator. It is to be noted that power spectral density (PSD) plots (similar to averaged FFT) instead of regular FFT plots are used for experimental results in order to avoid noise related problems. The rotor current spectra under light load (figure 15), clearly shows that problem can arise as many of the harmonics lie within $-10 \mathrm{~dB}$ of the $0.48 \mathrm{~Hz}$ fundamental component of the rotor.
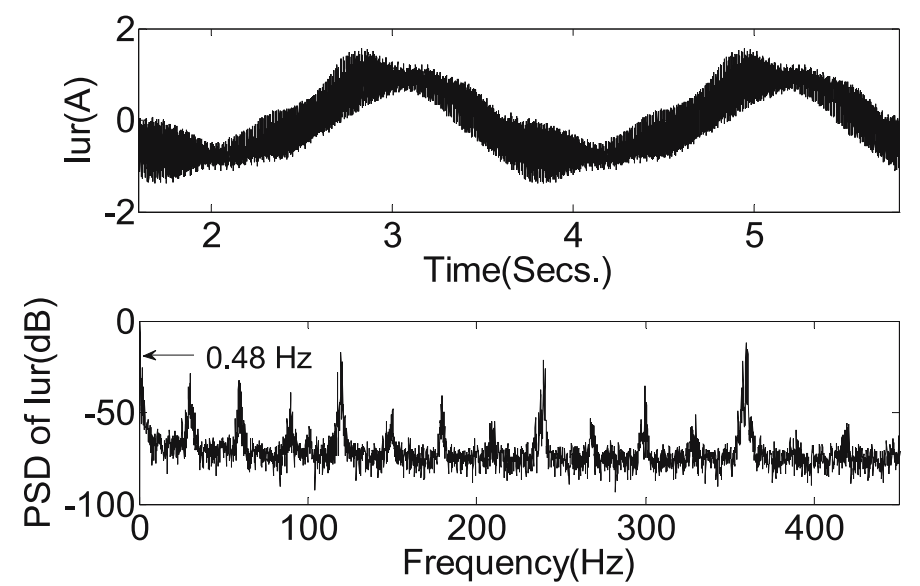

Figure 15. Experimental rotor line current $I_{u r}$ and its spectra under light load. There are several very large harmonic components distorting the rotor current. 


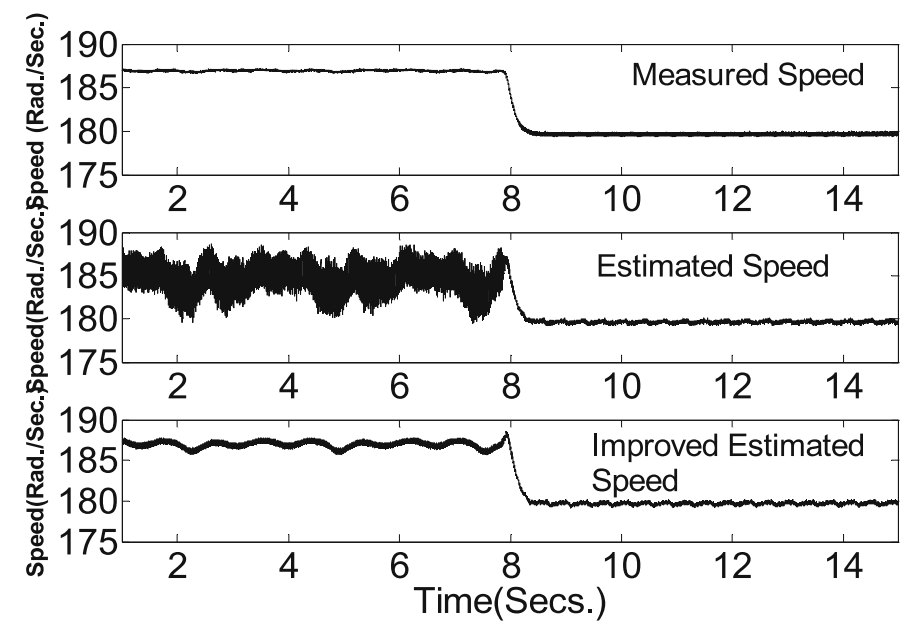

Figure 16. Comparative experimental results with improved speed estimation.

The algorithm in Datta \& Ranganathan (2002) was used in the same way as described to estimate the position and speed of the motor at light load and then with a step increase of load to full load. As can be seen from figure 16 (middle plot), the speed estimation has a lot of estimation error near no load compared to the measured speed (figure 16, top plot). The full load speed detection as well as the transient speed change capture is however quite acceptable. With the modification in the filtering scheme of speed detection as outlined in the simulation section, light load speed estimation can be improved significantly without jeopardizing the transient performance, as shown in figure 16 (bottom plot). The speed overshoot at the transition is also not significant. Again, the lower filter cut-off frequencies did not seem to have any effect on the estimated speed, even under transient and full-load condition. The corresponding estimate of $\cos \left(\rho_{2}\right)$ has been shown in figure 17. While not as good as figure 12, it seems

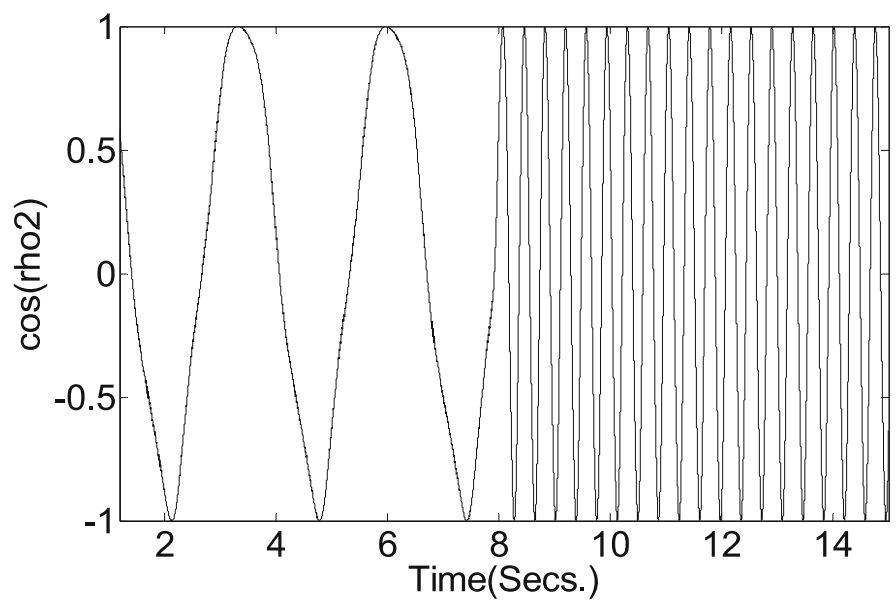

Figure 17. $\cos \left(\rho_{2}\right)$ computed for the bottom plot of figure 16 . 
adequate to give a reasonable speed estimate. There are some visible oscillations in the speed estimate and harmonic distortion in $\cos \left(\rho_{2}\right)$ under light load conditions most probably due to current harmonics as shown in figures 14 and 15 that could not be adequately filtered out. More involved filtering techniques are required to minimize them. However, this would most likely increase the on-line computational load. The author plans to implement these filters on a closed-loop wound rotor induction motor drive in near future.

\section{Conclusions}

The reasons for deterioration of position and speed estimation under light load condition of slip-ring induction motor-based drives were discussed in the paper. It was shown that space and time harmonics cause large distortion of rotor current resulting in poor quality of speed estimation near no-load conditions. However, it was shown through simulations as well as experiments that using proper filters for the stator, rotor current space vectors, estimates of magnetizing current magnitude and speed; position and speed estimation could be considerably improved without compromising the transient performance. The author is planning to implement these filters on a closed-loop wound rotor induction motor drive and present these results in a future publication.

The author would like to acknowledge University of Victoria, Canada Foundation for Innovation (CFI) and Natural Sciences and Engineering Research Council of Canada (NSERC) for the funding. The author would also like to extend his gratitude to Mr Qing Wu for helping with the experiments and Dr Michael McGuire for some discussion related to Butterworth digital filter applications.

\section{References}

Bose B K 2002 Modern power electronics (NJ: Prentice Hall)

Chatterjee J K, Perumal B V, Gopu N R 2007 Analysis of operation of a self-excited induction generator with generalized impedance controller. IEEE Trans. Energy. Conv. 22(2): 307-315

Datta R, Ranganathan V T 2002 Variable-speed wind power generation using doubly fed wound rotor induction machine-a comparison with alternative schemes. IEEE Trans. Energy. Conv. 17(3): 414-421

Datta R, Ranganathan V T 2002 A simple position-sensorless algorithm for rotor-side field-oriented control of wound-rotor induction machine. IEEE Trans. Indl. Electn. 17(3): 414-421

Jiang J, Holtz J 1995 Speed sensorless AC drive for high dynamic performance and steady state accuracy. Conference proceedings of the IECON 2(6-10): 1029-1034

Joksimovic G K 2007 Double-fed induction machine-dynamic modelling using winding function approach. Conference proceedings of IEMDC 694-697

Kim Y R, Sul S K, Park M H 1994 Speed sensorless vector control of induction motor using extended Kalman filter. IEEE Trans. Ind. Applns. 30: 1225-1233

Kron G 1951 Equivalent circuits of electric machinery (New York: John Wiley \& Sons. Inc.)

MATLAB 2007 (Natick, MA: The Mathworks Inc.)

Nandi S, Ahmed S, Toliyat H A, Bharadwaj R M 2003 Selection criteria of induction machines for speed-sensorless drive applications. IEEE Trans. Inds. Applns. 39(3): 704-712 
Poddar G, Ranganathan V T 2004 Direct torque and frequency control of double-inverter-fed slip-ring induction motor drive. IEEE Trans. Indl. Electn. 51(6): 1329-1337

Proakis J G, Manolakis D G 1997 Digital signal processing, principles, algorithms and application (India: Prentice-Hall)

Rajashekara K, Kawamura A Matsue (Eds) 1996 Sensorless control of AC drives (NY: IEEE Press) Sen P C 1997 Principles of electric machines and power electronics $2^{\text {nd }}$ edition (New York: John Wiley and Sons)

Vas P 1998 Sensorless vector and direct torque control (NY: Oxford) 